\title{
Optimal Sensor Placement for Airborne Contaminant Detection in an Aircraft Cabin
}

\section{Tengfei Zhang}

Student Member ASHRAE

\author{
Qingyan (Yan) Chen, Ph.D.
}

Fellow ASHRAE

\author{
Chao-Hsin Lin, Ph.D., P.E. \\ Member ASHRAE
}

\begin{abstract}
To monitor cabin air quality, infectious disease transmission, and intentional airborne contaminant releases in commercial aircraft cabins, it is necessary to place contaminant sensors in the cabins. Such sensors are often expensive, heavy, and bulky so they cannot be deployed in large quantity. This study used a Computational Fluid Dynamics (CFD) program to study how limited amount of sensors should be placed in an airliner cabin. This investigation first validated the CFD program with the experimental data of an airborne contaminant simulated by a tracer gas, air velocity and air temperature distribution obtained from a mockup of a twin-aisle aircraft cabin. Then the validated CFD program was used to study contaminant transport in a nine-row section of a Boeing 767 aircraft cabin with airborne contaminants released under different scenarios. By assuming different contaminant release rates and sensor sensitivities, the optimal sensor location and number were determined. It was found that the best location for a sensor is in the middle of the ceiling. The sensor detection capability depended on the contaminant source release rate and time as well as the sensor sensitivity. To detect contaminant effectively, this study also proposed a multiple-point sampler for each row.
\end{abstract}

\section{INTRODUCTION}

Currently only air temperature and barometric pressure are routinely measured in commercial aircraft cabins. The limited measurements are not sufficient when the environmental control system is not properly working and are not intended to detect or monitor air-quality incidents (NRC 2002). The National Research Council has thus suggested monitoring other air-quality characteristics on commercial aircrafts that include ozone, carbon monoxide, carbon dioxide, relative humidity and fine particulate matter.

Without the presence of appropriate sensors placed in the aircraft, information on contaminant transport cannot be obtained in a timely fashion. It is speculated that during the Sever Acute Respiratory Syndrome (SARS) outbreak in 2003, 22 passengers may have been infected by SARS in the flight from Hong Kong to Beijing (Olsen et al. 2003) due to possible release of the SARS viruses from an infected passengers. If a SARS sensor would be available and properly placed in the airplane, it might have provided the SARS release information during the flight so necessary protective measures, such as using oxygen or masks, may have been taken. Furthermore, after the use of the nerve agent sarin to attack the

Tengfei Zhang is a Ph.D. candidate, Qingyan (Yan) Chen is a professor in the School of Mechanical Engineering, Purdue University, West Lafayette, IN; and Chao-Hsin Lin is a technical fellow from the Boeing Commercial Airplanes Group, Seattle, WA. 
Tokyo subway system in 1995 and the anthrax cases in Florida and Washington, DC in 2001, there have been fears expressed of possible terrorist attacks by releasing chemical/biological agents in commercial airplanes. It would be potentially beneficial to obtain the release information of chemical/biological agents in advance to protect passengers and crew. Thus, a suitable placement of sensors on commercial airplanes can play a critical role in monitoring cabin air to create a comfortable, healthy and safe cabin environment for passengers and crew.

Typically, one would place a sensor at the air exhaust in an airliner cabin because the current air distribution system creates a mixing condition. The obtained measurement information, while useful, may be difficult to be used to find the contaminant sources (Zhang and Chen 2006). Because of the dilution of the contaminant due to the strong mixing effect, the detection would need very sensitive sensors after a long time of exposure. Thus when a contaminant is detected, the whole cabin may have been polluted. Previous research for airborne contaminant transport in a room showed that sensors can detect very different contaminant concentration levels at different locations (Zhai et al. 2003). They found that an early warning before the contaminant reached an occupant in the room was possible by placing sensors appropriately in the room. Since the room environment is similar to a cabin environment in terms of airflow and contaminant transport characteristics, it is also possible to obtain early warning data from the sensors if they are placed in proper locations inside the cabin.

\section{RESEARCH METHODS}

In order to place sensors suitably in an aircraft cabin, two research methods are available: experimental measurements and computer simulations. The experimental measurements would need to investigate sensor responses to different contaminants released at different locations. The best locations for sensors will be where the sensors can measure the highest contaminant concentrations in the least amount of time. Such experimental investigation would need a full-scale aircraft cabin. Due to different sensor sensitivities to different kinds of contaminant and many possible release scenarios, the experimental measurements can be very expensive and time consuming.

As compared to the experimental study, the computer simulations are much cheaper and more efficient. Computer simulations can use multizone models or Computational Fluid Dynamics (CFD) modeling. Arvelo et al. (2002) used a modified multizone model to study the optimum placement of chemical/biological contaminant sensors in a building with nine offices and a hallway. The contaminant transport time in a zone was not considered since the multizone model assumes instantaneous mixing in each zone. The multizone model can only provide some macroscopic information about the sensor placement. To obtain more accurate and detailed results one would turn to CFD modeling. Obenschain et al. (2004) studied optimal sensor placement during a chemical/biological contaminant threat in a city by using CFD modeling. In their study, the contaminant transport data was pre-computed and stored, and then was interpreted with a nomograph technique. Their results depend on the assumed meteorological conditions because different wind directions can make the paths of contaminant transport vastly different. Löhner and Camelli (2005) conducted detailed CFD study of optimal sensor placement for hazardous material transports around buildings. They 
compared different sensor placements in account for contaminant transport in possible meteorological conditions. A sensor was assumed to have detected the contaminant once the contaminant concentration exceeds a threshold level. Zhai et al. (2003) studied the optimal sensor placement for chemical/biological agent releases in buildings. Their results show that CFD simulation can be used to identify the proper location for the sensor deployment. Although the chemical/biological agent dispersion in enclosed environment is very fast, the sensors could give early warning to occupants in case of a terrorist attack. Clearly, the above review shows that CFD is more appropriate than the multizone model for this investigation.

In CFD simulations, one can assume hundreds of contaminant release scenarios and different sensor sensitivities, and can compare sensor performances at most possible locations in an aircraft cabin with little costs. However, the commonly used CFD modeling by solving the Reynolds-Averaged Navier-Stokes (RANS) equations with a turbulence model uses approximations so there are uncertainties in the numerical results. The CFD modeling should be validated with experimental data with similar flow features (Chen and Srebric 2002). The validated CFD program can then be used to identify the optimal sensor locations and number.

As discussed above, contaminant transport should be studied to properly place sensors. The governing equation for airborne gaseous contaminant transport in CFD modeling can be written as,

$$
\frac{\partial \phi}{\partial t}+(\vec{u} \cdot \vec{\nabla} \phi)=\Gamma_{\phi} \vec{\nabla}^{2} \phi+S_{\phi}
$$

where $\phi$ is the contaminant concentration, $t$ is time, $\vec{u}$ is the velocity vector, $\Gamma_{\phi}$ is the contaminant diffusion coefficient in the air, and $S_{\phi}$ is the contaminant source term. Similar governing equations can be obtained for continuity, momentum, energy, turbulent kinetic energy, and dissipation rate of turbulent kinetic energy to solve the airflow. This investigation used the Re-Normalization Group (RNG) $k-\varepsilon$ model (Yakhot et al. 1992) to model the turbulent flow as suggested by Chen (1995). The governing equations were then solved with the finite volume method by dividing the domain into many spatial cells. The discretized equations were obtained by integrating the governing equations with the cell volume and time and approximating some terms based on the second-order upwind scheme. Finally, the SIMPLE algorithm was applied to couple pressure and velocity to get the airflow solved.

\section{VALIDATION OF CFD METHOD}

As outlined in the previous section, the CFD method should be validated before studying the sensor placement in an airliner cabin. The experiment for validation used a mockup of a twin-aisle aircraft cabin with four-row seats as shown in Figure 1a. There was fluorescent lighting at the ceiling. Fourteen heated manikins made by painted metal boxes were used to simulate seated passengers. A lighting bulb and a fan were installed into each of the metal box to represent the metabolic heat generation of the sedentary passengers. The passenger capacity in the cabin was $50 \%$ with the occupied pattern shown in Figure 1b. Air was supplied at the ceiling level from linear slot diffusers and exhausted from the outlets at the floor level on the 
side walls. An $\mathrm{SF}_{6}$ source was introduced at the head level of the middle passenger seated in the third row to simulate an airborne contaminant source as indicated in Figure 1.

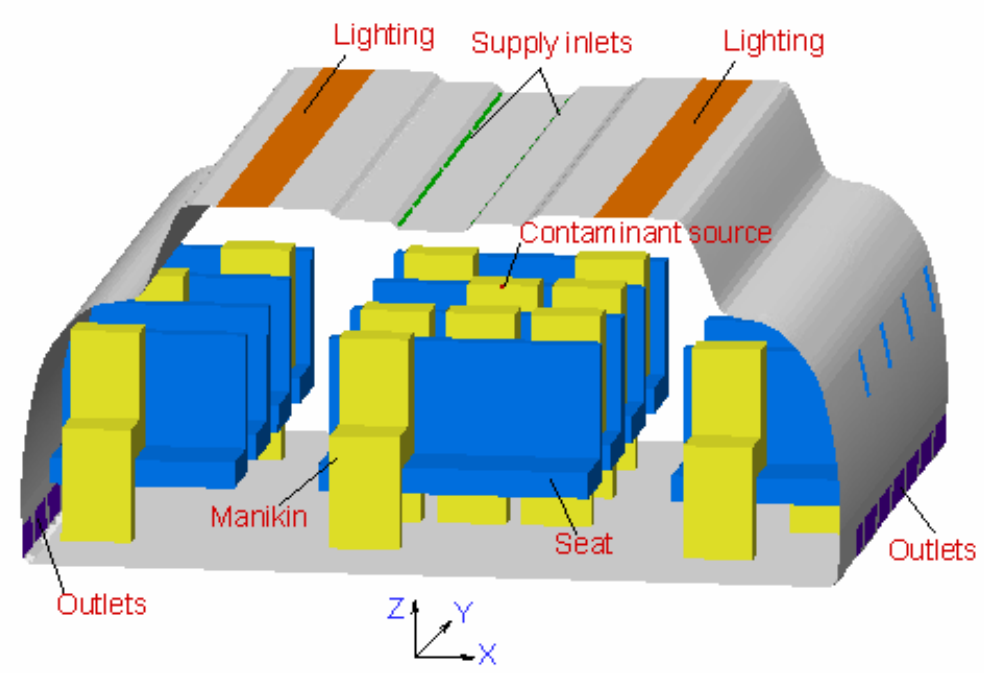

(a)

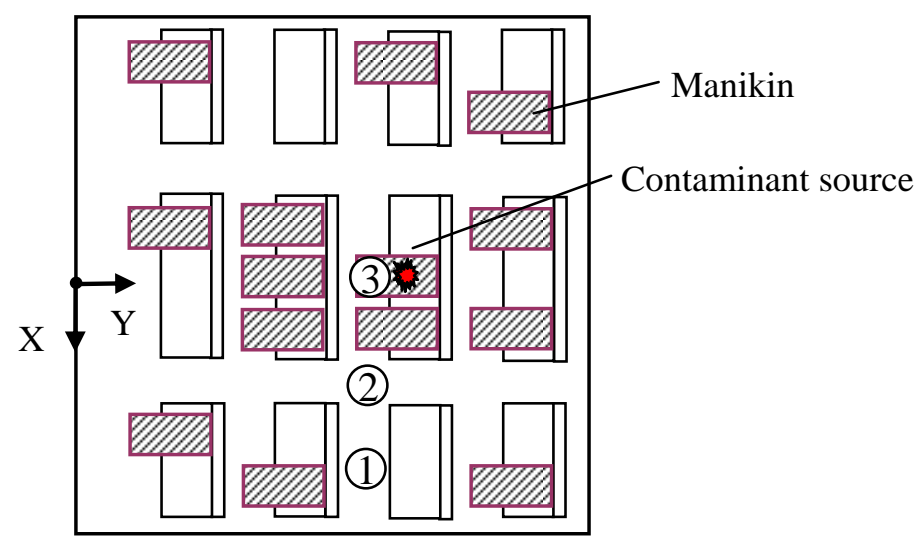

(b)

Figure 1. The mockup of a twin-aisle aircraft cabin for validation: (a) Schematic; (b) Top view.

Two ultrasonic anemometers were used to measure air velocities and temperatures. The probe of each anemometer was mounted on a removable pole to measure at different locations. The accuracy of the anemometers for velocity components was $0.005 \mathrm{~m} / \mathrm{s}$ with $1 \%$ error, and for air temperature was $0.025{ }^{\circ} \mathrm{C}$ with $1 \%$ error. A photo acoustic multi-gas monitor with a multi-point sampler was used to measure $\mathrm{SF}_{6}$ concentrations. The sampling tubes were mounted at different heights at eight vertical poles to extract the cabin air to the multi-gas monitor. The accuracy of the system was $0.01 \mathrm{ppm}$ and the repeatability was $1 \%$ of the measured values.

During the measurement of airflow, after changing the probe position of the anemometers the environmental control system was stabled for six minutes to record next data. At the end 
of the measurements in one section, the thermo-flow boundary conditions were compared with the initial ones to ensure no changes during the experiment. In fact, two sets of experimental data were obtained by two groups of researchers at different time. The two sets of results were almost the same.

A CFD simulation was performed for the case used in the experiment. The cabin geometry in the CFD study was built with GAMBIT (http://www.fluent.com) and 2,841,200 tetrahedral cells were generated by using TGrid scheme. A commercial CFD program, FLUENT (http://www.fluent.com), was used to solve the distributions of airflow, air temperature and contaminant concentrations simulated by $\mathrm{SF}_{6}$.

Figure 2(a) shows the airflow pattern in a cross section through the third-row seats. The high-velocity air from the supply diffusers went to both sides of the cabin and then moved up in the central region to form two large eddies. The two large eddies were not symmetrical partly because the air supplies from the two inlets were not symmetrical. In addition, the thermal boundary conditions and the passenger occupation pattern in the cabin mockup were also not symmetrical. There are significant discrepancies between the simulated and measured airflow patterns. For example, the high-velocity air in the region near the ceiling on the right aisle can not be reproduced by CFD. The computed airflow at the left side was stronger than the measured one. The discrepancies might be caused by the exact airflow conditions from the supply diffusers were not implemented in the CFD simulation. The airflow conditions from the supply diffusers were estimated by using omni-directional hot sphere anemometers because the probes of the ultrasonic anemometers were too large for the diffusers. The flow directions from the diffusers were estimated by smoke visualization. The airflow pattern was very sensitive to the flow conditions from the diffusers. Unless a laser Doppler anemometer was used, it would be very difficult to determine the exact flow conditions from the diffusers.

Figure 2(b) also compares the airflow pattern on the mid-plane along the longitudinal direction. Generally, the airflow went up to the ceiling level that was driven by the two large eddies in a cross section and by thermal buoyancy force. The airflow near the ceiling was divided into two streams above the second-row seat, one moving forwards and another backwards. The flow feature was captured very well by the CFD modeling. Because the experiment showed that the air supply from the third row was highly three dimensional, the longitudinal velocity component was very significant. To keep the flow in the entire cabin balanced, the longitudinal velocity components in the entire cabin should be evener. It can also be found that the calculated thermal plume from the passenger at the third row was not as strong as the measured one. This is probably due to the uniform manikin surface temperature $\left(31^{\circ} \mathrm{C}\right)$ used in CFD simulation. The uniform surface temperature was hard to be obtained in the experiment.

Besides the airflow pattern, the distributions of air temperature and contaminant concentration simulated by $\mathrm{SF}_{6}$ were also studied. Figure 3a compares the temperature profiles at three different locations as shown in Figure 1b. The measurements were done in eight locations, but not all the results are shown here due to limited space available in this paper. The vertical coordinate is corresponding to the cabin height. Because of the mixing airflow characteristics, the air temperature in the cabin was quite uniform. Since the low part of position 3 was inside 
of a manikin, the air temperature in the low part of the figure was not computed and shown. Figure $3 \mathrm{~b}$ compares the calculated and measured $\mathrm{SF}_{6}$ concentration distribution at the same three locations. Again the uniform concentration distributions were observed because of the good mixing effect in the cabin. At position 3, a peak concentration was found at height of around $1.7 \mathrm{~m}$ due to its proximity to the $\mathrm{SF}_{6}$ source. Although CFD predicted a much higher $\mathrm{SF}_{6}$ concentration at this position, it is difficult to say that the measured value is more accurate. This is because the flow in the region was not steady that could cause a major error in the measurement. Yuan et al. (1999) found similar problems caused by unstable flow in an office with displacement ventilation.

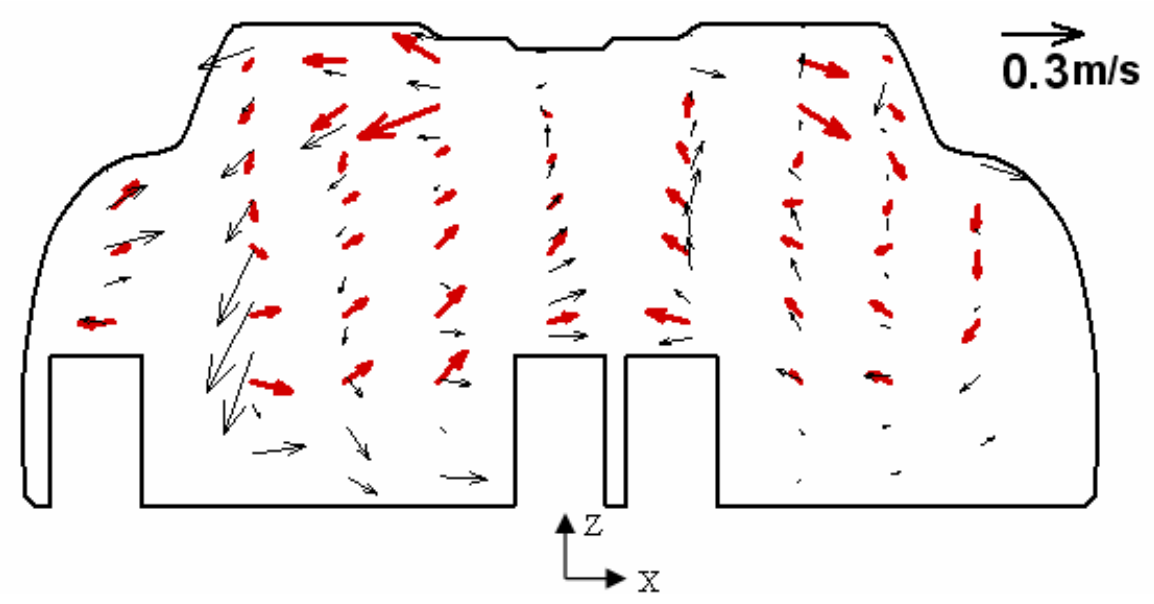

(a)

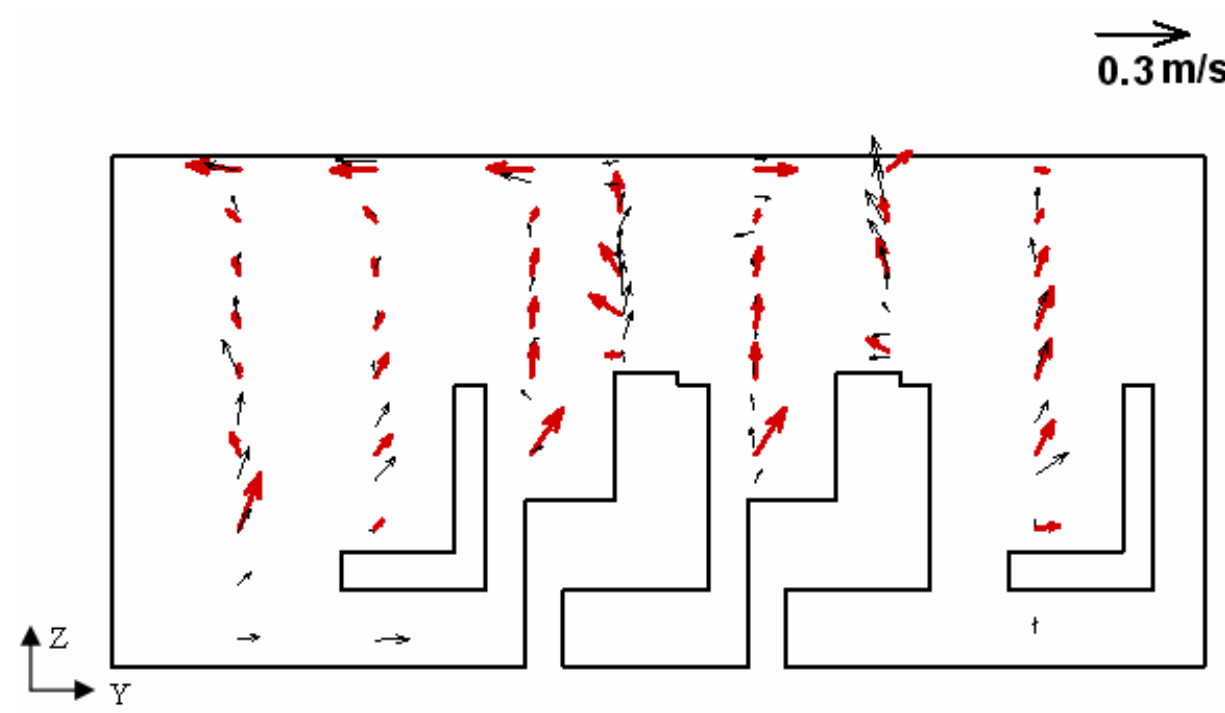

(b)

Figure 2. Comparison of the airflow pattern measured (bold vectors in red color) and computed (light vectors in black color): (a) in the cross section; (b) in the mid-section along the longitudinal direction. 
In fact, the authors have previously used the experimental data from other enclosed spaces, such as rooms, to validate the CFD program with good agreement between the computed results and the measured data (Zhang and Chen 2007). In those experimental measurements, the air supply diffusers were simple slot openings and some airflows were also of similar low Reynolds numbers. We could assume with confidence that the discrepancies shown above are due to the complex airflow from the diffusers. Thus, the comparison of the CFD results with the experimental data concludes that the CFD program with the RNG k- $\varepsilon$ model is a useful tool that can reasonably predict airflow, air temperature, and contaminant transport in the mockup of the twin-aisle aircraft cabin. There are discrepancies between the computed results and the measured data, especially for the airflow pattern, which was most likely caused by the errors associated with boundary conditions. It was impossible to obtain accurate boundary conditions with our current measuring techniques. Nevertheless, the CFD model can be used to study airflow and contaminant transport.
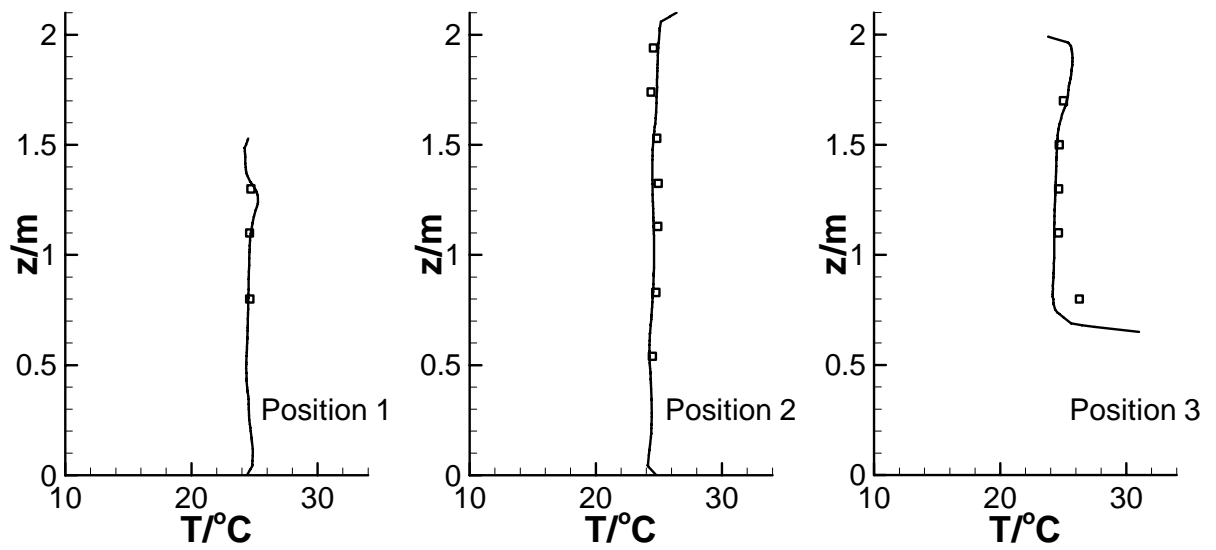

(a)
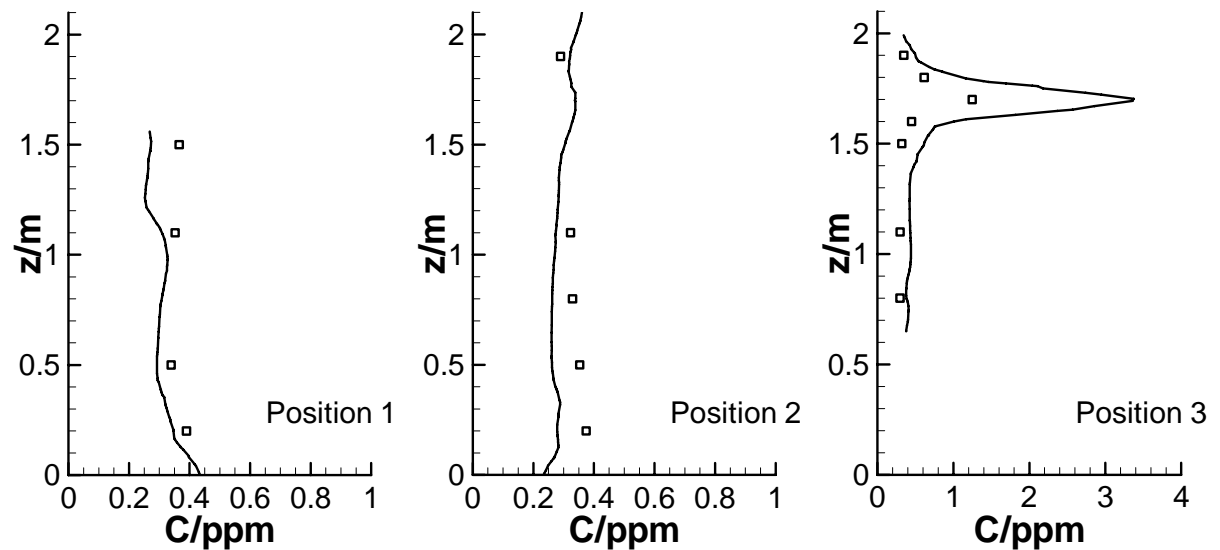

(b)

Figure 3. Scalar variable comparison between CFD results (lines) and measurement (symbols): (a) for temperature; (b) for contaminant concentration.

\section{CASE SETUP}


After the validation, this study used the CFD method to find the optimal sensor locations and number in a Boeing 767-300 aircraft cabin as shown in Figure 4. The best locations should be where sensors can measure the highest contaminant concentration within the shortest time. The optimal number should allow sensors to detect all possible airborne contaminants in the cabin. This cabin model is the same as the one used by Lin et al. (2005a, b). Each row had seven seats that were fully occupied by heated manikins that had head, torso, thigh, legs and feet for each manikin. Four strips of heat sources were installed at the ceiling to simulate lighting devices. Two small windows and two aisles were also created at both sides. Two linear inlets at the ceiling were used to supply high-velocity air to both sides of the cabin. The air was exhausted from the outlets on the side walls near the floor level.

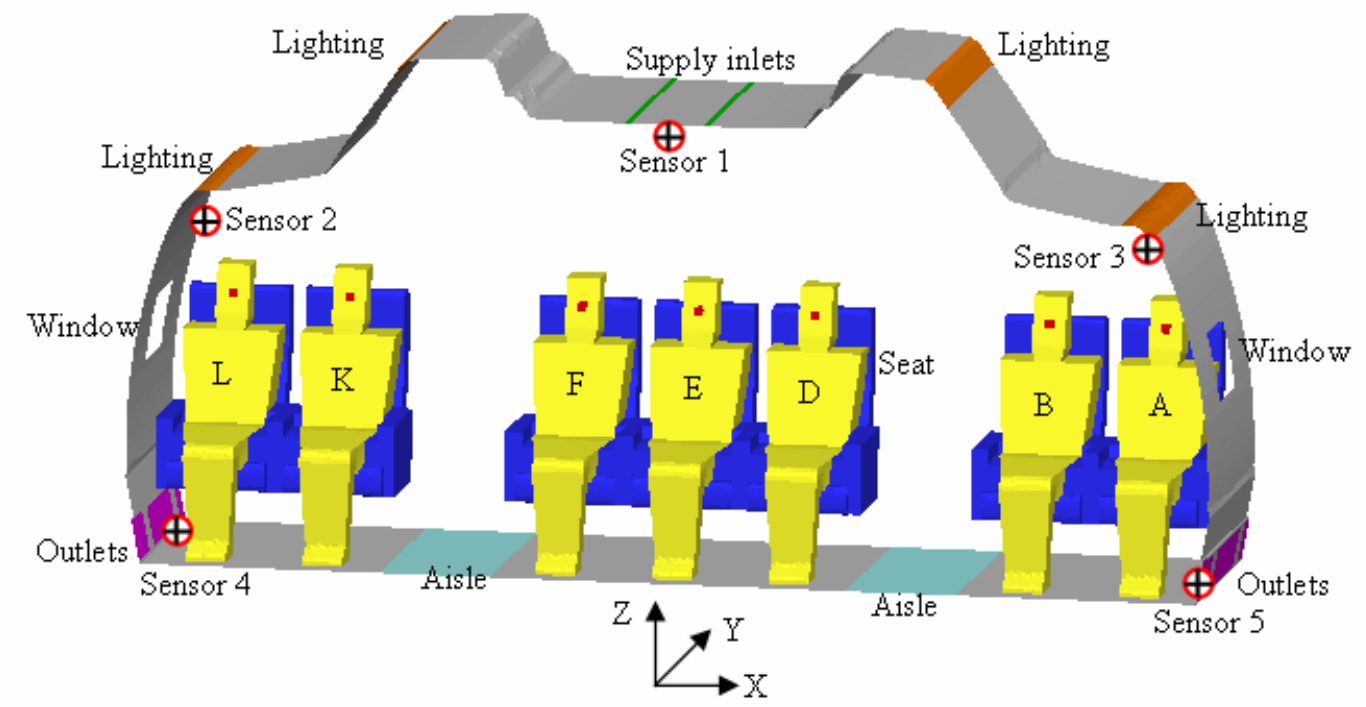

Figure 4. Geometry of one-row section of the Boeing 767-300 cabin.

Table 1 summarizes the thermal and flow boundary conditions used in the simulations for a cruising Boeing 767 airplane. All the surface temperatures were obtained from the on-site measurements. The average air temperature in the cabin was controlled at $24^{\circ} \mathrm{C}$. The heat sources in the aircraft cabin were from the passengers and lights. The CFD model did not consider the heat sources from electronic devices, drinks, and meals. Thus, the supply air temperature in Table 1 could be higher than that used during actual airplane operation. The CFD modeling did not include radiation. However, the convective heat was used as input in the CFD modeling and the ratio of convective and radiative heat for the heat sources was estimated according to ASHRAE Handbook - Fundamentals (ASHRAE 2005).

The gaseous contaminant concentration from the supply air was assumed to be zero. Gaseous contaminants were released at the nose positions of the manikins with three different rates: low rate of $1.0 \times 10^{-7} \mathrm{~m}^{3} / \mathrm{s}$, moderate rate of $1.0 \times 10^{-6} \mathrm{~m}^{3} / \mathrm{s}$, and high rate of $1.0 \times 10^{-5}$ $\mathrm{m}^{3} / \mathrm{s}$. Two release scenarios were assumed: one was continuous and another was for $30 \mathrm{~s}$. This study further assumed the sensor response time to a contaminant to be zero (no lag). In fact, the sensor response time usually ranges from 10 to $60 \mathrm{~s}$ (http://www.afcintl.com/) for common indoor chemical contaminants. A contaminant was thought to be detected by a 
sensor once the concentration exceeded a threshold value (the sensor sensitivity) ranging from $0.01 \mathrm{ppm}$ to $10 \mathrm{ppm}$.

Table 1. Thermal and flow boundary conditions used in the CFD model

\begin{tabular}{cccc}
\hline Item & Value & Item & Value \\
\hline Supply air temperature & $19.5{ }^{\circ} \mathrm{C}$ & $\begin{array}{c}\text { Floor temperature } \\
\text { (outside both aisles) }\end{array}$ & $23{ }^{\circ} \mathrm{C}$ \\
$\begin{array}{c}\text { Supply airflow rate } \\
\text { Ceiling temperature (within } \\
\text { both supply inlets) }\end{array}$ & $\begin{array}{c}\text { liters/s per } \\
\text { passenger }\end{array}$ & $\begin{array}{c}\text { Window temperature } \\
\text { Temperature of } \\
\text { passenger surfaces } \\
\text { Lighting heat } \\
\text { generation rate }\end{array}$ & $13{ }^{\circ} \mathrm{C}$ \\
$\begin{array}{c}\text { (beyond both supply inlets) } \\
\text { Temperature of side walls }\end{array}$ & $25{ }^{\circ} \mathrm{C}$ & $30.3{ }^{\circ} \mathrm{C}$ \\
$\begin{array}{c}\text { Floor temperature (within } \\
\text { both aisles) }\end{array}$ & $18{ }^{\circ} \mathrm{C}$ & $12.5 \mathrm{~W} /$ row \\
\hline
\end{tabular}

With limited computing resources available, it is not realistic to study the sensor placement in a whole Boeing 767 airplane. Instead, this investigation used a section of cabin with ninerow seats with periodical boundary conditions at both ends as shown in Figure 5. The length of this nine-row cabin is sufficiently long to consider contaminant transport in the longitudinal direction and can adequately simulate the thermal and flow boundary conditions. The periodical boundary conditions used in the two ends imply that the cabin was infinitely long.

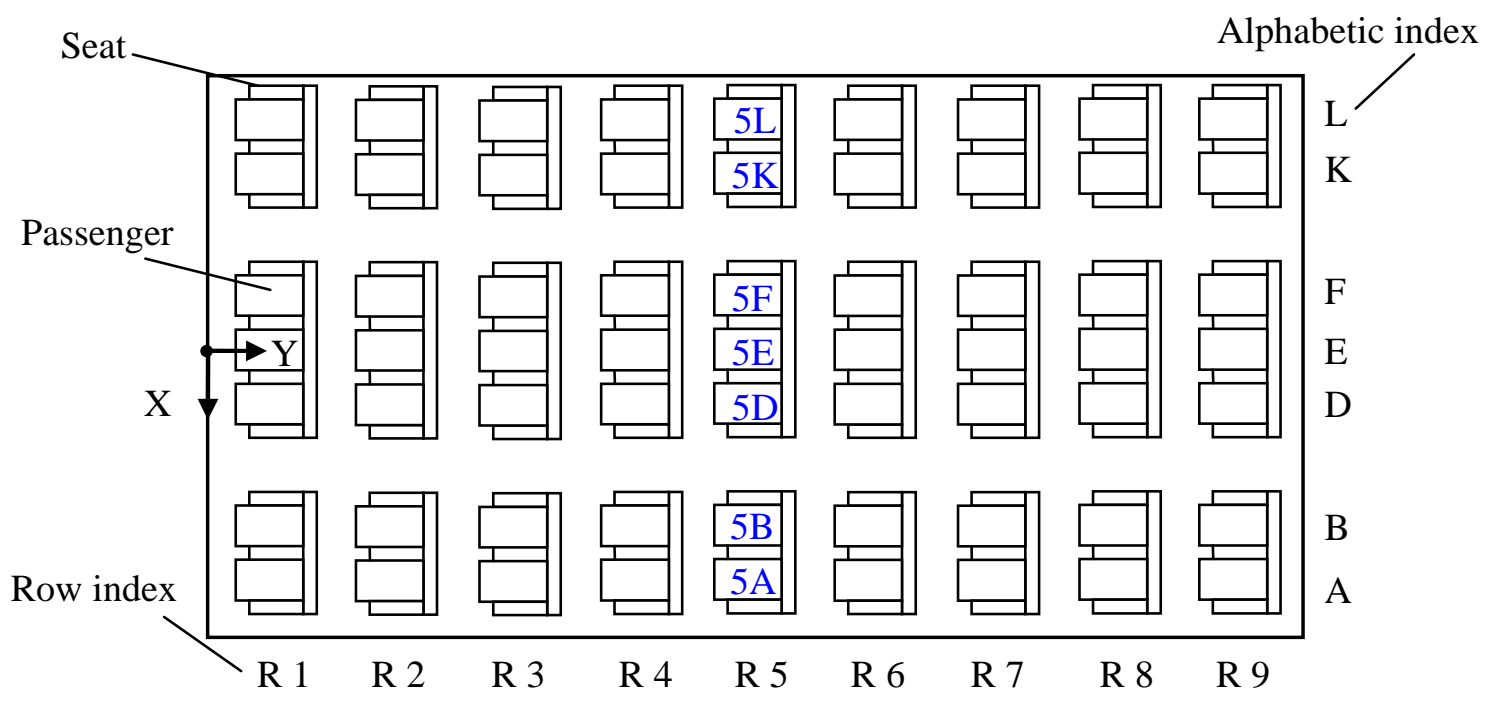

Figure 5. Layout of the nine-row section of the Boeing 767-300 cabin with seat index.

A total of 5,326,493 tetrahedral cells were created in this nine-row section of cabin by using TGrid scheme. Two solvers are available in FLUENT, the segregated solver and the coupled solver. The segregated solver solves the algebraic equations sequentially. The coupled solver solves the equations simultaneously, thus requiring more computing memory. This investigation used the segregated steady-state solver to compute airflow. Both the segregated 
steady-state solver and the segregated unsteady-state solver, were used to compute contaminant concentration with fixed airflow pattern.

\section{RESULTS AND DISCUSSIONS}

\section{Characteristics of Contaminant Transport in the Aircraft Cabin}

Since airborne contaminant transport is subjected to the airflow characteristics, it is necessary to analyze the airflow in the cabin to understand how the contaminant was transported. Figure 6a shows the airflow pattern across the fifth row. Very similar to the twinaisle mockup, high-velocity air from the supply inlets generated two large eddies that mixed the air in the cabin. The airflow pattern was again not symmetrical since the boundary profiles from the supply air were asymmetric. Thermal plumes can be seen for the passengers in the central seating area but are not evident for the passengers near the cabin windows because of the strong jet effect from the air supply. Figure $6 \mathrm{~b}$ shows the airflow pattern in the midsection along the longitudinal direction. Generally the airflow went up in the mid-section of the cabin due to the eddy effect and thermal plumes, which is similar to that for the twin-aisle cabin mockup.

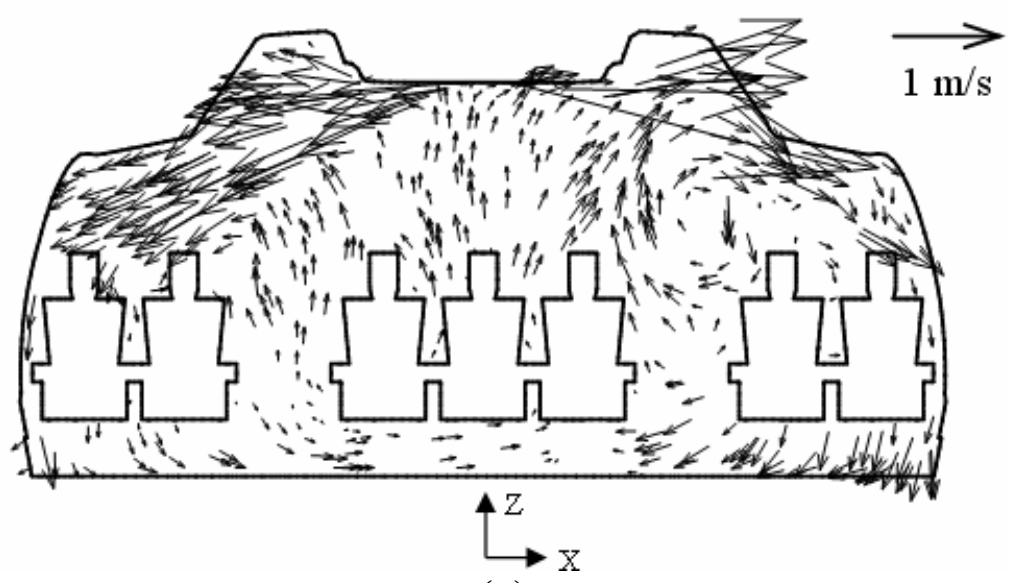

(a)
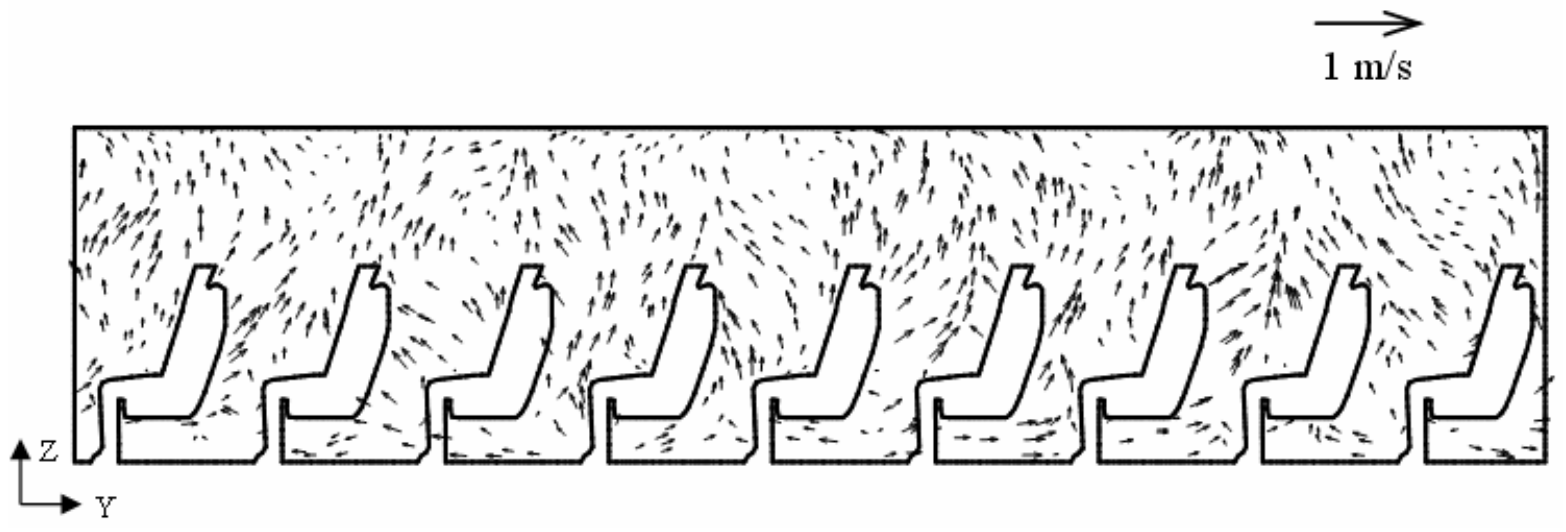

(b)

Figure 6. Airflow patterns in the nine-row section of the Boeing 767-300 cabin: (a) in the cross section through row 5; (b) in the mid-section along the longitudinal direction. 
Figure 7 shows the steady-state concentration fields at two typical sections when the contaminant was released continuously from passenger $5 \mathrm{E}$ at the moderate rate. The concentration in the region above passenger $5 \mathrm{E}$ was very high due to the thermal plume effect. Since Boeing 767 was designed with minimum flow along the longitudinal direction, the decay of the contaminant concentration was very fast. The region with high contaminant concentration was confined to the surrounding area around the source. This imposes some challenges in using a small amount of sensors to detect all the contaminants that will be discussed later in the paper.

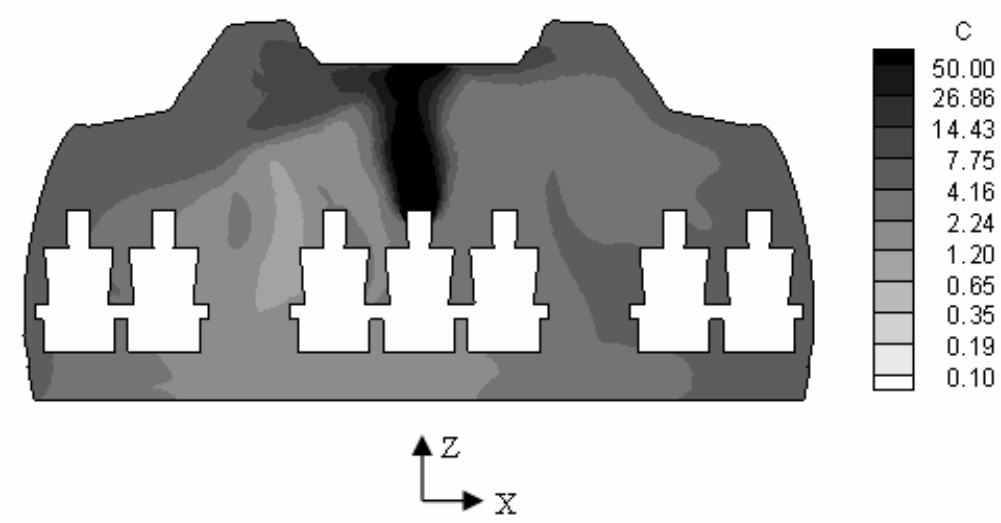

(a)
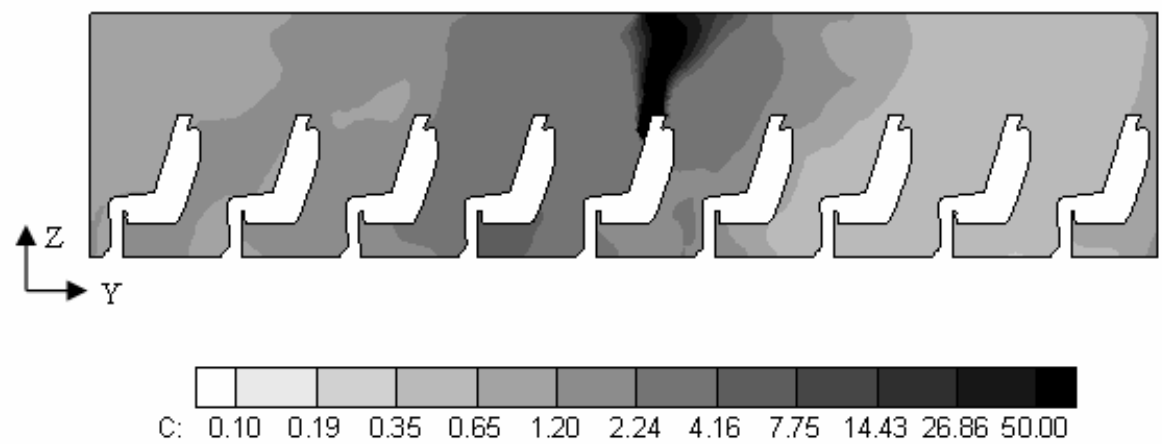

(b)

Figure 7. Contaminant concentration distribution under steady state when released from passenger $5 \mathrm{E}$ at the moderate rate: (a) in the cross section through row 5; (b) in the mid-section along the longitudinal direction.

\section{Sensor Placement in a Cross Section}

Sensors at different locations may respond quite differently to various airborne contaminant releases. A sensor at a suitable location may detect the contaminant easier and faster. This study first investigated the best sensor location in a cross section through row 5 by examining five possible sensor locations as shown in Figure 4. Sensor 1 was in the middle of the ceiling, 
sensor 2 and 3 were at the top of the sidewalls below the stowage bins, and sensor 4 and 5 were at the sidewalls close to the floor near the outlets. Each passenger in the row was assumed to release a different kind of contaminant at the moderate rate continuously or for 30 S.

Figure 8 shows the time to reach a concentration of $0.1 \mathrm{ppm}$ at the five sensor locations. When the contaminants were released continuously, the concentrations can reach $0.1 \mathrm{ppm}$ at all the five sensor locations within $80 \mathrm{~s}$. However, with a 30-second release, the concentration at sensors 2 and 4 could never reach $0.1 \mathrm{ppm}$ for the release from passenger $5 \mathrm{~A}$. This is because the airflow pattern in the cross section contained two large eddies. Sensors 2 and 4 were very sensitive to the release of contaminants with the same large eddy, as such released from passengers $5 \mathrm{E}, 5 \mathrm{~F}, 5 \mathrm{~K}$ and $5 \mathrm{~L}$. Because passengers $5 \mathrm{~A}, 5 \mathrm{~B}$, and $5 \mathrm{D}$ were in the other large eddy and the two large eddies did not mix well, sensor 2 and 4 responded to the contaminant released by passengers 5A, 5B and 5D poorly. If only one sensor is available, the results in Figure 8 indicate that the location for sensor 1 is the best choice due to its overall performance. This location is also convenient for sensor installation. The time of detection at other levels of concentration led to the same conclusions.

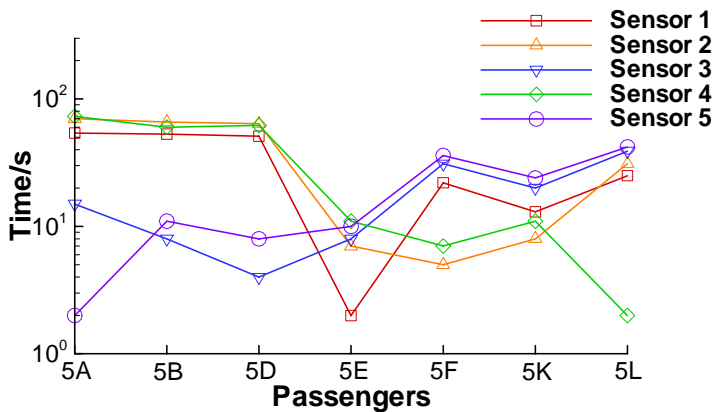

(a)

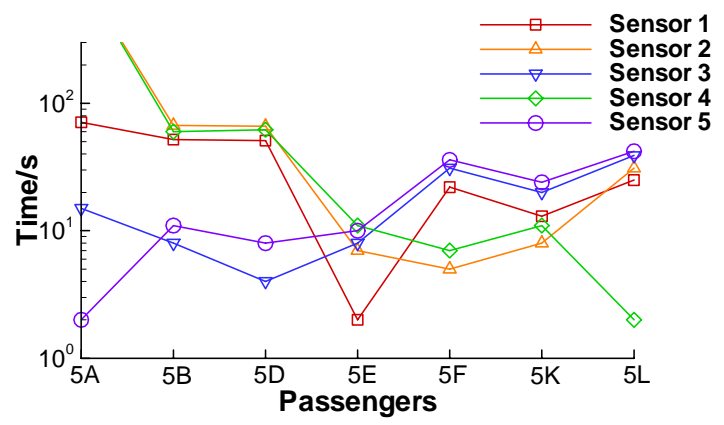

(b)

Figure 8. Time to reach a concentration of $0.1 \mathrm{ppm}$ at the five sensor locations for different contaminants released at the moderate rate from the seven passengers in the fifth row: (a) with a continuous release and (b) with a 30-second release.

\section{Sensor Placement along a Longitudinal Direction}

To study the sensor performance along a longitudinal direction, nine sensors were placed in the mid-ceiling with one at each row. The sensor performance was examined when a contaminant source was released with both scenarios at the moderate rate from passengers 5E and $5 \mathrm{~K}$, respectively. Figure 9 shows the time needed to reach different levels of contaminant concentrations. Not surprisingly, the farther away from the contaminant source, the longer was the time needed to reach the same level of concentration at these locations. It is also easier to detect the contaminant if it was released continuously than that released within a short period (e.g. $30 \mathrm{~s}$ in this investigation).

With $0.01 \mathrm{ppm}$ as the threshold concentration for detection, all the nine sensors could detect the contaminant within $100 \mathrm{~s}$ for both release scenarios from both sources. The contaminant concentration could reach $0.1 \mathrm{ppm}$ at all sensor locations within $200 \mathrm{~s}$ with the continuous release for both sources. While for the 30 -second release scenario, only the 
sensors from row 4 to row 7 could reach $0.1 \mathrm{ppm}$ for source from passenger $5 \mathrm{E}$, and the sensors from row 1 to row 6 from passenger $5 \mathrm{~K}$.

If the concentration threshold level was $1 \mathrm{ppm}$ and the detection time was set as $200 \mathrm{~s}$, only four sensors from row 3 to row 6 could detect the contaminant release from passenger 5E with the continuous release, and two sensors in row 4 and 5 for the 30 -second release. While for contaminant from passenger 5K, within 200s four sensors from row 2 to row 5 could detect the contaminant for the continuous case, and one sensor at row 5 for the 30-second release. For $10 \mathrm{ppm}$ level only the sensor at the fifth row would work for both release scenarios for passenger $5 \mathrm{E}$, and the sensor failed to detect contaminant from passenger $5 \mathrm{~K}$. It may not be realistic to place one sensor in each row, unless the sensor is very inexpensive and light and needs little power. Otherwise, the results show that sensitive sensors are needed in such a cabin.

The sensor performance for contaminants from other passengers looked similar and is not presented repeatedly for brevity.

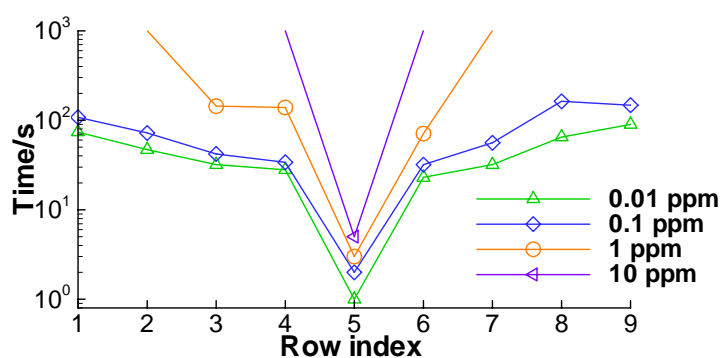

(a)

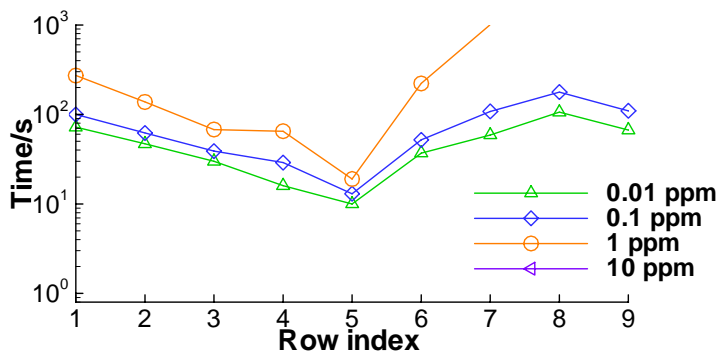

(c)

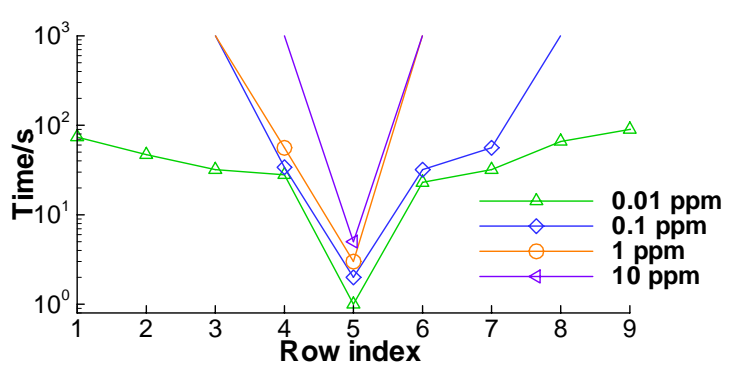

(b)

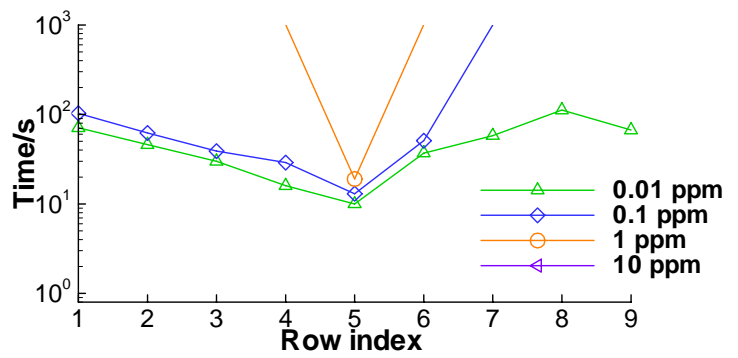

(d)

Figure 9. Time to reach different levels of contaminant concentration at the nine sensor locations for contaminants released at the moderate rate: (a) from passenger 5E with continuous release; (b) from passenger $5 \mathrm{E}$ with 30 -second release; (c) from passenger $5 \mathrm{~K}$ with continuous release; (d) from passenger $5 \mathrm{~K}$ with 30 -second release.

\section{Sensor Detection Capability}

As outlined in previous sections, multiple or highly sensitive sensors are required to detect all the contaminants in the Boeing 767 cabin. The number of sensors required is a function of sensor sensitivity. To reveal the function, a sensor assumed with different sensitivities was placed at the central ceiling as a demonstration case. The different contaminants were released with three different rates from the nine $\mathrm{E}$ and nine $\mathrm{K}$ column passengers. 
Figure 10 depicts the contaminant source number could be detected by the sensor when released by the $\mathrm{E}$ and $\mathrm{K}$ column passengers with the three rates under two scenarios (continuously or for $30 \mathrm{~s}$ ). When the release rate was high and continuous, a sensor with sensitivity of $2.5 \mathrm{ppm}$ is sufficient to detect all the contaminants from the E column passenger (Figure 10a). For the low release rate, a sensor with $0.5 \mathrm{ppm}$ sensitivity could only detect the contaminants released from the same row. If the sensor has a detectable threshold concentration of $10 \mathrm{ppm}$, none of the contaminants could be detected for the case with the low release rate. For the 30-second release scenario as shown in Figure 10b, the sensor with the same sensitivity detected fewer contaminants compared with that for the continuous release scenario. Generally, the sensor is a little more difficult to detect the contaminants released by the $\mathrm{K}$ column passengers than those by the $\mathrm{E}$ column passengers, when compared Figures 10(a) and 10(b) with Figures 10(c) and 10(d).

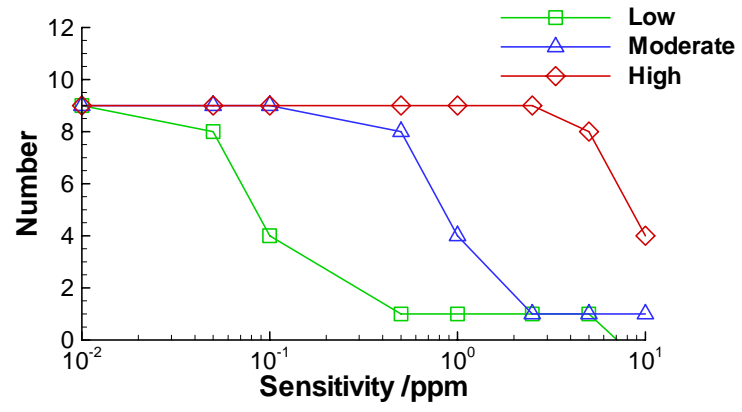

(a)

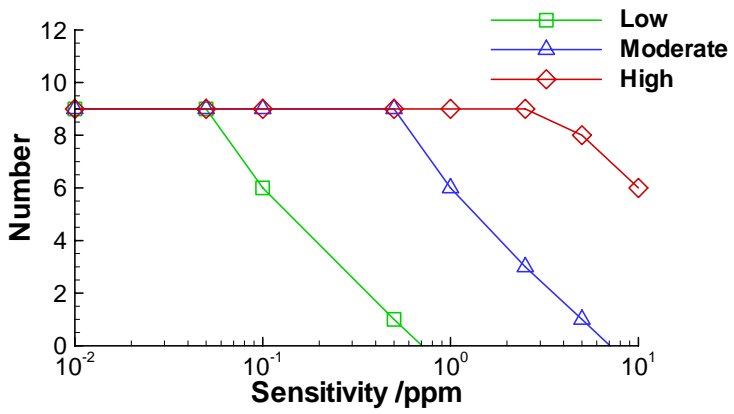

(c)

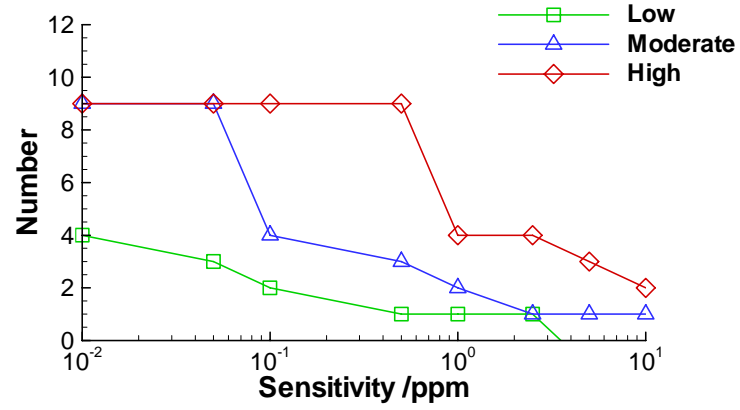

(b)

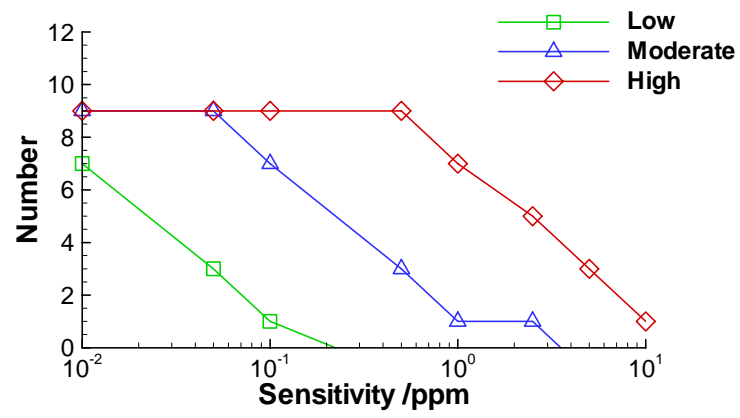

(d)

Figure 10. The contaminant source number could be detected by the ceiling sensor with three release rates: (a) for continuous release from the E column passengers, (b) for 30second release from the $E$ column passengers, (c) for continuous release from the $K$ column passengers, and (d) for 30 -second release from the $\mathrm{K}$ column passengers.

The results show that it was easier to detect a contaminant released at a high rate with a sensitive sensor. It was also a little easier to detect the contaminants from those passenger seated in the central seats than those from near windows. Since the sensor was located at the center of the ceiling and the flow pattern was upward in the center of the cabin, the contaminants from the passengers seated in the center can be easily transported to where the sensor was located, as illustrated in Figure 8. The results for the contaminants released from other passengers led to the same conclusions, although they are not presented in this paper. 


\section{The Multiple-Sampling-Point Sensor}

As depicted in Figure 9, a single sensor can take a long time to detect or even cannot detect the contaminants released from several rows away. If it is not feasible to use many sensors, one possibility is to collect air by a multiple-point sampler. The collected air would be analyzed by a sensor. The multiple-point sampler would draw air in the middle of the ceiling in each row simultaneously with the same sampling flow rate. Thus the air collected by the sampler has the averaged contaminant concentration from the sampling locations. This investigation assumed only one sensor was used for every nine rows of cabin. The contaminant sources were assumed from passenger $5 \mathrm{E}$ and $5 \mathrm{~K}$ to represent the releases from the central passenger and a side passenger. The sensing time of the multi-sampling-point sensor to detect both the sources from the $\mathrm{E}$ and $\mathrm{K}$ column passengers is shown in Figure 11. The sensing time increased slightly with the increase of the threshold concentration. It took shorter time to detect contaminant released at a high rate than at a low rate, which is the same as the single-point sensor.

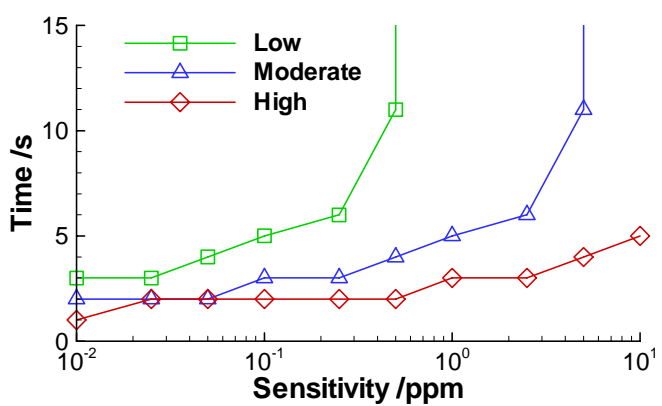

(a)

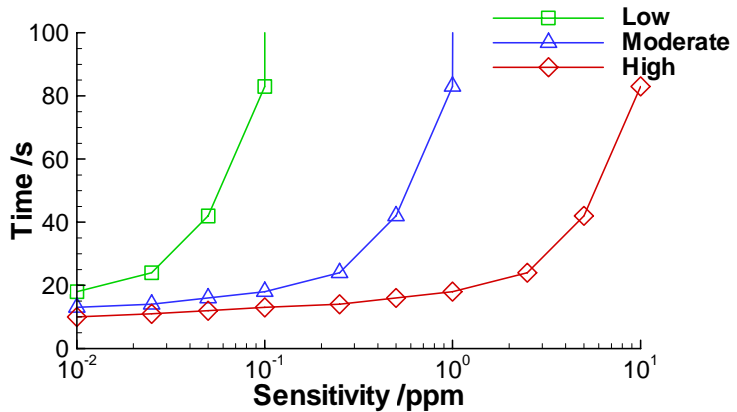

(b)

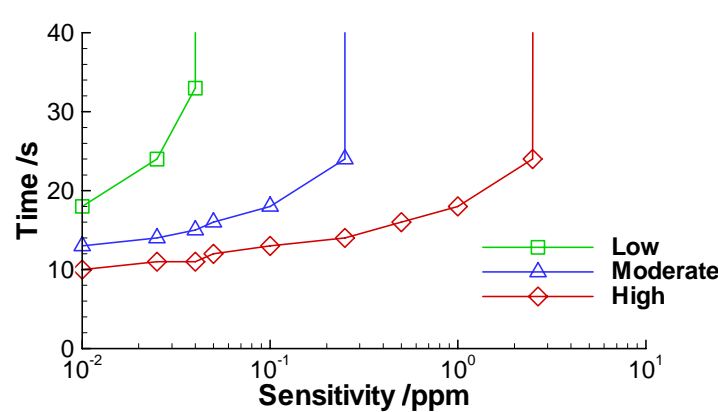

(c)

Figure 11. The sensing time associated with the multiple-sampling-point sensor: (a) for source from passenger $5 \mathrm{E}$ with continuous and 30 -second release; (b) for source from passenger $5 \mathrm{~K}$ with continuous release; (c) for source from passenger $5 \mathrm{~K}$ with $\mathbf{3 0}$-second release.

If the multi-point sensor could detect a release from passenger $5 \mathrm{E}$ or $5 \mathrm{~K}$, a contaminant release from any of the other $\mathrm{E}$ or $\mathrm{K}$ column passengers in this nine-row cabin could be detected, since each row had a sampling point in the middle ceiling. In other words, the sensing time of this sensor for any contaminant released from Passenger 1E to 9E (and the same for Passenger $1 \mathrm{~K}$ to $9 \mathrm{~K}$ ) would be the same. This is because with similar contaminant transport characteristics at each row, the time needed to transport the contaminant released 
from a passenger to the sampling point in the middle ceiling from each row would be the same. However, without the multi-point sampler, it would take much longer time to detect the sources located several rows away from the sensor or even cannot detect them at all as shown in Figure 9. Only at a high threshold concentration level, the sensor with a multiple-point sampler behaved poorer than the single-point sensor. For example, when the source was released from passenger $5 \mathrm{E}$ continuously in the moderate rate, the single-point sensor still could detect the source if the sensor was placed in the fifth row as shown in Figure 10a at 10 ppm of sensor sensitivity. For the same scenario, a sensor with a multiple-point sampler could not detect the source as shown in Figure 11a with an infinite sensing time. This is because the concentration was diluted to a level below 10 ppm by the air from other sampling points.

\section{CONCLUSIONS}

This investigation validated a CFD model computed with the commercial CFD program FLUENT using the experimental data from a mockup of a twin-aisle aircraft cabin. Because of the difficulties in obtaining accurate flow boundary conditions from the air supply diffusers, there are significant discrepancies between the computed and measured airflow patterns. However, the simulation for the distributions of air temperature and a tracer-gas contaminant concentration agreed with the measured ones. Thus, FLUENT is an acceptable tool to study contaminant transport in aircraft cabins.

After the validation, FLUENT was used to find the best locations for contaminant sensor placement. This study used a nine-row section of a twin-aisle aircraft cabin with periodic boundary conditions at both ends to simulate an infinitely long Boeing 767 airplane. The results show that the cabin air was very well mixed in a cross section as reflected by the uniform distribution of the gaseous contaminant. Since the airflow along the longitudinal direction was insignificant, the contaminant decay was very fast.

The optimal sensor location in a cross-section was found to be in the middle ceiling if only one sensor was used by comparing five possible sensor locations. The sensor can detect the contaminants better if the release rate was higher, the release time was longer, and the sensor was more sensitive. The sensor could detect contaminant released from any passenger in the nine-row cabin, if it was placed in the middle of the ceiling in row 5 under the following scenarios:

\begin{tabular}{|c|c|c|}
\hline Release rate $\left(\mathrm{m}^{3} / \mathrm{s}\right)$ & Release time $(\mathrm{s})$ & Sensor sensitivity $(\mathrm{ppm})$ \\
\hline $1.0 \times 10^{-5}$ & Infinite & $\leq 2.5$ \\
\hline $1.0 \times 10^{-5}$ & 30 & $\leq 0.5$ \\
\hline $1.0 \times 10^{-6}$ & Infinite & $\leq 0.1$ \\
\hline $1.0 \times 10^{-6}$ & 30 & $\leq 0.05$ \\
\hline $1.0 \times 10^{-7}$ & Infinite & $\leq 0.01$ \\
\hline $1.0 \times 10^{-7}$ & 30 & $\leq 0.005$ \\
\hline
\end{tabular}

A single-point sensor took a long time to detect contaminant releases from several rows away. This investigation thus proposed a multiple-point sampler at each row. A sensor was then used to measure the air taken by the multiple-point sampler. This would significantly improve the detectivity of contaminant in a cabin. 


\section{ACKNOWLEDGEMENTS}

This project is funded by the U.S. Federal Aviation Administration (FAA) Office of Aerospace Medicine through the Air Transportation Center of Excellence for Airliner Cabin Environment Research under Cooperative Agreement 04-C-ACE-PU. Although the FAA has sponsored this project, it neither endorses nor rejects the findings of this research. The presentation of this information is in the interest of invoking technical community comment on the results and conclusions of the research.

\section{REFERENCES}

Arvelo, J., A. Brandt, R.P. Roger, and A. Saksena. 2002. An enhancement multizone model and its application to optimum placement of CBW sensors. ASHRAE Transactions 108 (2): 818-25.

ASHRAE. 2005. ASHRAE Handbook - Fundamentals. Atlanta: American Society of Heating, Refrigerating and Air-Conditioning Engineers, Inc.

Chen, Q. 1995. Comparison of different $k-\varepsilon$ models for indoor air flow computations. Numerical Heat Transfer, Part B 28: 353-69.

Chen, Q., and J. Srebric. 2002. A procedure for verification, validation and reporting of indoor environment CFD analyses. HVAC\&R Research 8(2): 201-16.

Lin, C.H., R.H. Horstman, M.F. Ahlers, L.M. Sedgwick, K.H. Dunn, J.L. Topmiller, J.S. Bennett, and S. Wirogo. 2005a. Numerical simulation of airflow and airborne pathogen transport in aircraft cabins - Part 1: Numerical simulation of the flow field. ASHRAE Transactions 111(1):755-63.

Lin, C.H., R.H. Horstman, M.F. Ahlers, L.M. Sedgwick, K.H. Dunn, J.L. Topmiller, J.S. Bennett, and S. Wirogo. 2005b. Numerical simulation of airflow and airborne pathogen transport in aircraft cabins - Part 2: Numerical simulation airborne pathogen transport. ASHRAE Transactions 111(1): 764-68.

Löhner, R., and F. Camelli. 2005. Optimal placement of sensors for contaminant detection based on detailed 3D CFD simulations. Engineering Computations 22 (3): 260-73.

NRC (National Research Council). 2002. The airliner cabin environment and the health of passengers and crew. Washington, DC: National Academy Press.

Obenschain, K., J. Boris, and G. Patnaik. 2004. Using CT-ANALYST ${ }^{\mathrm{TM}}$ to optimize sensor placement. Proceedings of SPIE. Orlando, Florida, 5416: 14-20.

Olsen, S.J., H.L. Chang, T.Y. Cheung, A.F. Tang, T.L. Fisk, S.P. Ooi, H.W. Kuo, D.D. Jiang, K.T. Chen, J. Lando, K.H. Hsu, T.J. Chen, and S.F. Dowell. 2003. Transmission of the severe acute respiratory syndrome on aircraft. New England Journal of Medicine 349(25): 2416-22.

Yakhot, V., S.A. Orzag, S. Thangam, and T.B. Gatski. 1992. Development of turbulence models for shear flows by a double expansion technique. Physics of Fluids A: Fluid Dynamics 4(7): 1510-20.

Yuan, X., Q. Chen, L.R. Glicksman, Y. Hu, and X. Yang. 1999. Measurements and computations of room airflow with displacement ventilation. ASHRAE Transactions 105(1): 340-52.

Zhai, Z., J. Srebric, and Q. Chen. 2003. Application of CFD to predict and control chemical and biological agent dispersion in buildings. International Journal of Ventilation 2(3): 25164.

Zhang, T., and Q. Chen. 2006. Identification of contaminant sources in enclosed environments by inverse CFD modeling. Indoor Air. In press.

Zhang, T., and Q. Chen. 2007. Novel air distribution systems for commercial aircraft cabins. Building and Environment 42(4): 1675-84. 